Edición Extraordinaria. p.p.1057-1066

Memorias del VIII Encuentro Nacional de Experiencias en Enseñanza de la Biología y la Educación Ambiental. III Congreso Nacional de Investigación en Enseñanza de la

Biología.

\title{
SECUENCIA DIDACTICA SOBRE LA ESTRUCTURA INTERNA DE LOS SERES VIVOS EN ESTUDIANTES DE JORNADA SABATINA, EN ALGECIRAS HUILA
}

\section{SEQUENCE TEACHING ON THE INTERNAL STRUCTURE OF LIVING IN STUDENT DAY SATURDAY IN ALGECIRAS HUILA}

\section{Cabiativa Hernández Eduar Nicolás ${ }^{1}$, Cuellar López Zully²}

\section{RESUMEN}

La Práctica Pedagógica I en la Licenciatura de Ciencias Naturales de la Universidad Surcolombiana de Neiva-Huila, permite intervenir en el aula, para desarrollar la trama entre el saber disciplinar y el pedagógico-didáctico. La secuencia didáctica propone esta interacción, desde variables como el contexto, dificultades en la enseñanza y aprendizaje de las ciencias naturales, ideas previas de los estudiantes, sus intereses, contenidos conceptuales, procedimentales y actitudinales y un diario de campo que permite la reflexión de la puesta en práctica de la secuencia. Así de esta manera el estudiante profesor reflexiona su práctica inicialmente desde la planificación de su clase al proponer actividades para la instrucción de las ciencias naturales, que en este caso enriquezca y facilite la comprensión en la enseñanza de la estructura interna de los seres vivos. Esta experiencia pedagógica tiene contexto especial, ya que se realiza con jóvenes y adultos del ciclo $4\left(8^{\circ}\right.$ y $9^{\circ}$ grado) que eligen la educación no formal, en la modalidad sabatina, por dificultades de tipo, social, personal y económicas que se le presentan para seguir la escuela regular. Esta situación se agrava porque viven en una zona que actualmente se encuentra en conflicto de orden público como lo es el municipio de Algeciras Huila. A pesar que usualmente estos estudiantes reciben una educación de segunda, con la planeación y aplicación de la secuencia didáctica se logró que los estudiantes reciban una educación con las mismas exigencias de la educación formal donde se evidencia la relación saber disciplinar y pedagógico-didáctico.

Palabras Claves: secuencia didáctica, saber disciplinar y pedagógico-didáctico.

\begin{abstract}
The experience developed in the Pedagogical Practice I students in the Bachelor of Natural Sciences of the University Surcolombiana Neiva, Huila, allows them to intervene in the classroom, to develop that frame between disciplinary knowledge and pedagogical-didactic. The didactic sequence proposed this interaction, since variables such as context, difficulties in teaching and learning in the natural sciences, previous ideas of students, their interests, conceptual, procedural and attitudinal and field diary that allows reflection implementation of
\end{abstract}

Estudiante de VIII semestre de la Licenciatura de Ciencias Naturales: Física, Química y Biología de la Universidad Surcolombiana. Email: du_ar007@ hotmail.com

${ }^{2}$ Docente de la Licenciatura de Ciencias Naturales: Física, Química y Biología de la Universidad Surcolombiana. Email: zully.cuellar@usco.edu.co 
Memorias del VIII Encuentro Nacional de Experiencias en Enseñanza de la Biología y la Educación Ambiental. III Congreso Nacional de Investigación en Enseñanza de la Biología.

the sequence. So this way the student teacher reflects his practice initially from planning of its kind to propose activities for the instruction of the natural sciences, which in this case will enrich and facilitate understanding in the teaching of the internal structure of living things. This educational experience is of particular context, as is done by the student teacher in initial training, youth and adults by cycle 4 (8th and 9th grade) who choose non-formal education, in the Saturday mode, type difficulties, social, political and economic issues will have to follow the regular school. This situation is aggravated because they live in an area that is currently in conflict with public order such as the municipality of Algeciras Huila. Although usually these students receive an education second, with the planning and implementation of the teaching sequence was achieved that students receive a quality education with the same demands of formal education and thus encourage them to continue studying.

Keywords: teaching sequence, disciplinary knowledge and pedagogical-didactic.

\section{Introducción}

La formación de futuros profesores en Ciencias Naturales, en la Licenciatura en Ciencias Naturales de la Universidad Surcolombiana de Neiva -Huila Colombia busca formar profesionales de la educación que lleven a cabo prácticas profesionales donde confluyan el saber disciplinar con la

pedagogía-didáctica. Formación que busque contribuir a resolver tensiones de los últimos treinta años entre los que consideran que la formación de los maestros debe hacerse fundamentada en un alto dominio de las ciencias, y consideran secundario en la formación de maestros el saber de la pedagogía y didáctica. $\mathrm{Y}$ los que consideran que la base fundamental es la pedagogía y didáctica como su discurso práctico, y que, el solo dominio de un conocimiento científico o técnico no determina las habilidades, ni destrezas que provee la inteligencia pedagógica a la práctica educativa (Ibarra, 2011). Situación planteada también a nivel internacional por diferentes autores, como Neus Sanmarti (2002), al analizar que "la mayoría de los modelos de formación se caracterizan por una separación entre la formación 'en contenidos científicos' y formación en 'contenidos didácticos' (y todos estos contenidos separados de la práctica). Implícitamente se cree que si una persona 'sabe' de la materia y conoce teorías generales sobre cómo enseñar, sabrá aplicarlas a la enseñanza de cada contenido".

Situación que se agudiza cuando nos damos cuenta que la gran mayoría de los profesores en formación inicial no quieren ser maestros y están en la licenciatura como segunda opción. Por eso desde nuestro trabajo como docentes formadores nos preguntamos: ¿Cómo desde la práctica pedagógica un profesor en formación puede desarrollar su saber profesional?

Para los profesores en formación inicial, la Practica Pedagógica I es el momento de iniciar la profesión docente, la interacción entre el conocimiento de la temática a enseñar (disciplina) y la pedagogía se hace indispensable y su deseo o rechazo por ser docente se manifiestan. La facultad de educación de la Universidad Surcolombiana considera que en las diferentes etapas de formación que anteceden a la práctica pedagógica, el estudiante universitario debe tener la oportunidad de interactuar con el contexto educativo, para vivenciar de manera holística el rol del educador, esto solo se presenta en el seminario de Didáctica I y II. Desde allí iniciamos con la práctica pedagógica 
Edición Extraordinaria. p.p.1057-1066

Memorias del VIII Encuentro Nacional de Experiencias en Enseñanza de la Biología y la Educación Ambiental. III Congreso Nacional de Investigación en Enseñanza de la

Biología.

como un preámbulo a lo que será su práctica en las Instituciones educativas de Neiva. Es así como la práctica pedagógica I y II, se convierte en el espacio donde esta relación se materializa, el más apropiado para contrastar y aplicar de una manera transversal elementos técnicos, científicos, comunicativos y metodológicos en procura de la construcción de sujetos sociales, protagonistas de su propia historia, individual y colectiva, e inicie la construcción de un saber profesional que le permita incidir críticamente en su transformación y contribuir a su desarrollo (Facultad de Educación, 2011). Esta práctica profesional implica, procesos de planeación, enseñanza y reflexión acerca de un tópico, con ella ganará confianza, así que pueda reducir las novedades y sorpresa cuando enfrenta problemas de enseñanza, desarrollando gran capacidad de respuesta al enfrentar estas situaciones, formar criterio propio e innovar. La planeación para intervenir en el aula tiene que ver con la reflexión de preguntas como: ¿Qué variables hay que tener en cuenta para la planeación de una clase?, ¿Qué finalidad tiene la clase? ¿Cómo van organizados los contenidos a enseñar? ¿Cuáles son los momentos de una clase? ¿Qué actividades van en cada momento? ¿Qué contenidos están articulados con esas actividades? Para esto se piensa en una secuencia didáctica de clase la cual depende de varias variables como son: el contexto, las dificultades en la enseñanza y aprendizaje de las ciencias naturales, las ideas previas de los estudiantes y sus intereses, la secuencia en sí y un diario de campo que permita la reflexión. Entendido este como un instrumento que nos permite interrogar y desentrañar el sentido de la realidad, constituyéndose en el testigo biográfico fundamental de nuestra experiencia (Porlán, 1993).

\section{Metodología}

Para el estudiante de Práctica I organiza su intervención en el aula en cinco momentos (ver tabla1) con base a las preguntas antes mencionadas, aclarando que los momentos se dan no de manera lineal sino paralela.

\begin{tabular}{|c|c|c|}
\hline MOMENTOS & CATEGORIA & ACTIVIDADES \\
\hline $\begin{array}{c}\text { Primer } \\
\text { momento }\end{array}$ & $\begin{array}{l}\text { El contexto: caracterización de la institución } \\
\text { educativa, del grupo de estudiantes } \\
\text { (intereses e ideas previas sobre el tópico a } \\
\text { aprender). }\end{array}$ & $\begin{array}{l}\text { Observación participante y } \\
\text { aplicación de Cuestionarios, } \\
\text { tabulación y análisis de } \\
\text { resultados, dialogo con el } \\
\text { cooperador. }\end{array}$ \\
\hline & $\begin{array}{l}\text { Búsqueda en la literatura sobre ideas } \\
\text { previas, dificultades de Enseñanza y } \\
\text { Aprendizaje del tópico a aprender. }\end{array}$ & Registro y citación de autores. \\
\hline $\begin{array}{c}\text { Tercer } \\
\text { momento }\end{array}$ & $\begin{array}{l}\text { Planeación teniendo en cuenta los } \\
\text { anteriores momentos, para determinar: } \\
\text { finalidad, estándar, contenidos } \\
\text { conceptuales, procedimentales y } \\
\text { actitudinales, secuencia de clase son una } \\
\text { fase de introducción, desarrollo y cierre. }\end{array}$ & $\begin{array}{l}\text { Registro en } \\
\text { planeación. }\end{array}$ \\
\hline
\end{tabular}

\footnotetext{
${ }^{3}$ Cooperadora se le llama a la profesora titular de la Institución Educativa donde se realizará la práctica.
} 
Edición Extraordinaria. p.p.1057-1066

Memorias del VIII Encuentro Nacional de Experiencias en Enseñanza de la Biología y la Educación Ambiental. III Congreso Nacional de Investigación en Enseñanza de la Biología.

\begin{tabular}{|c|l|l|}
\hline $\begin{array}{c}\text { Cuarto } \\
\text { momento }\end{array}$ & $\begin{array}{l}\text { Aplicación de la planeación realizada que } \\
\text { lleva a la transformación y producción del } \\
\text { saber profesional. }\end{array}$ & Se observa la clase y se filma. \\
\hline $\begin{array}{c}\text { Quinto } \\
\text { momento }\end{array}$ & Reflexión de la intervención realizada. & $\begin{array}{l}\text { Diario de campo, observación } \\
\text { del video, dialogo con el } \\
\text { estudiante profesor. Entrega de } \\
\text { informe final sobre el proceso } \\
\text { anterior. }\end{array}$ \\
\hline
\end{tabular}

Tabla 1. Momentos para la intervención en el aula.

En el marco de un estudio de caso como investigación cualitativa de tipo descriptivo, con análisis de contenido, analizamos los resultados obtenidos al aplicar los cinco momentos anteriores, con un estudiante profesor que desarrolla su práctica pedagógica en el municipio Algeciras Huila, de composición social campesina y se encuentra en zona de conflicto armado. El estudiante profesor diseña y aplica su secuencia didáctica para el ciclo 4 (grados $8^{\circ}$ y $9^{\circ}$ ) de educación media con una población de 75 estudiantes. Para el análisis se toma el informe del Proyecto de Acción Pedagógica (PAP) presentado por un estudiante de Practica Pedagógica I del 2015 semestre- A y las grabaciones realizadas a las clases.

\section{Resultados y Discusion.}

Para el primer momento se realizan las actividades ya descritas y el resultado es el siguiente en cuanto la caracterización del grupo de estudiantes: ciclo 4 (grados $8^{\circ}$ y $9^{\circ}$ ) de educación media, entre 15 y 75 años de edad y de los cuales algunos de ellos llevaban sin estudiar 2, 10, 25 y hasta 40 años. De esto se deduce la dificultad a la hora de enseñar ya que los estudiantes no tienen una continuidad en su aprendizaje y por ende tiende a olvidar lo poco aprendido. A partir de esto, en dialogo con el cooperador se orienta la clase sobre cómo es la estructura interna de los seres vivos, según como está en su planeación. Para conocer las ideas de los estudiantes sobre cómo es la estructura interna de los seres vivos se propuso el siguiente interrogante:

Al frente de cada ser vivo u objeto, escribe si está conformado de células o tejidos o las dos. Explica tu respuesta: a. Bacteria. b. Piedra. c. Hormiga. d. Árbol. e. Hongo. f. León. g. Niño. Las respuestas obtenidas se interpretaron y están representadas en un consolidado final, en la tabla 2.

\begin{tabular}{|l|c|c|}
\hline \multicolumn{1}{|c|}{ INTERPRETACION } & $\begin{array}{c}\text { N }{ }^{\circ} \text { DE } \\
\text { ESTUDIANTES }\end{array}$ & $\%$ \\
\hline $\begin{array}{l}\text { Estudiantes que no tienen claro la diferencia entre una } \\
\text { célula y tejido. }\end{array}$ & 43 & 57.3 \\
\hline $\begin{array}{l}\text { Estudiantes que no tienen claro la diferencia entre un ser } \\
\text { vivo y no vivo. }\end{array}$ & 18 & 24 \\
\hline Estudiantes que tuvieron en cuenta las células y tejidos. & 8 & 10.7 \\
\hline Estudiantes que no entendieron la pregunta. & 6 & 8 \\
\hline Total & 75 & 100 \\
\hline
\end{tabular}

Tabla 2. Respuestas de los estudiantes. 
Edición Extraordinaria. p.p.1057-1066

Memorias del VIII Encuentro Nacional de Experiencias en Enseñanza de la Biología y la Educación Ambiental. III Congreso Nacional de Investigación en Enseñanza de la Biología.

De lo anterior, el $57.3 \%$ de los estudiantes presentan dificultades para diferenciar las células y tejidos. Por ejemplo: El estudiante E15: "asevero que las bacterias presentan tejidos y que las hormigas solo tienen células pero no tejidos", el $24 \%$ no tienen clara la diferencia entre un ser vivo y no vivo así como el estudiante E25:" indica que la piedra presenta células y tejidos", el $10.7 \%$ contesta desde sus percepciones adecuadamente y a su vez propone diferencias entre los seres vivos, tomando como ejemplo la respuesta del E32: "El árbol posee células y tejidos pero no sistemas, la hormiga, el niño y el león tienen células y tejidos y además tienen sistemas, el hongo solo tiene células, la bacteria es una célula y la piedra no es un ser vivo".

Para el momento dos encontramos en la literatura lo siguiente (algunos apartes de lo encontrado): En cuanto las dificultades de la enseñanza de cómo es la estructura interna de los seres vivos, en contextos escolares, el estudio de las células se enfoca casi exclusivamente en relación con el cuerpo humano, como una derivación de estudios anatómicos. Este enfoque resulta apropiado si se tiene en cuenta que el propio cuerpo resulta a los estudiantes más conocido que el de diferentes organismos. Sin embargo, puede derivar en una visión antropocéntrica que hace difícil imaginar a la célula como unidad estructural de todos los organismos (Mengascini, 2006). A esto se le suma la dificultad para diferenciar lo vivo y lo no vivo, entender la diversidad de especies que hay entre las microscópicas y macroscópicas (Rivera, 2013). En relación con esto, es frecuente encontrar que los estudiantes, por considerar a la naturaleza celular como una característica particular de los animales, duden respecto de naturaleza celular o del carácter multicelular de otros seres vivos, como árboles, helechos u hongos (Menegaz \& Mengascini, 2005).

De acuerdo a lo anterior se decide proponer actividades relacionadas con hongos, plantas, fuera del ser humano y experiencias de laboratorio.

En el tercer momento con base en lo anterior se propone secuenciación didáctica, organizada desde una pregunta, y dividida en tres momentos: introducción, desarrollo y cierre como podemos apreciar en la tabla 3.

\section{Actividad 1.}

\section{Actividades}

\section{INTRODUCCIÓN O INICIO}

Planteamiento de la situación problema experimental, para trabajar en grupos de 3 estudiantes los estudiantes recrean, escriben, diseñan, indagan y proponen soluciones a la situación problema de Juan.

\section{¿Cómo están formadas las cosas?}

Juan visita a su abuelo Federico que hace mucho tiempo que no lo veía. Al llegar nota que la casa está muy desordenada y muy sucia. Juan admira mucho a su abuelo Federico porque él es un gran médico y además le gusta leer muchos textos sobre biología. Juan al ver que su abuelo se concentraba tanto en el trabajo y leyendo estos libros, no le quedaba tiempo para hacer oficio. Juan se caracteriza por ser un niño muy amable, decide ordenar y limpiar la casa. Mientras que recogía la 
Edición Extraordinaria. p.p.1057-1066

Memorias del VIII Encuentro Nacional de Experiencias en Enseñanza de la Biología y la Educación Ambiental. III Congreso Nacional de Investigación en Enseñanza de la Biología.

basura encontró una serie de objetos que le llamaron mucho la atención los cuales eran un corcho, una cebolla, una naranja descompuesta, un tarro con agua muy turbia y babosa y un palillo de una paleta que acababa de comerse su abuelo. Juan curiosamente interrumpe a su abuelo y le pregunta ¿Abuelo, cómo están formados estos objetos?

¿Cuál crees que sea la explicación que le ha dado el abuelo Federico a Juan?

Luego los grupos socializan los resultados y analizan. Con la directriz del profesor organizar con los estudiantes la información recogida y a partir de ello, preguntar a los estudiantes cómo comprobar esas hipótesis.

\section{Actividad 2.}

\section{DESARROLLO}

Con las propuestas de los estudiantes de solución a las hipótesis, construir una guía experimental que se plasmará en el tablero, donde ellos indiquen el nombre, objetivos, y preguntas a partir de la situación problema de Juan. Luego en grupos de 6 los estudiantes recrean, escriben, dibujan, observan y aplican la guía experimental propuesta y creada a partir de sus ideas previas.

Organizar con los estudiantes la información recogida y a partir de ello crear una tabla comparativa que se plasmara en el tablero, donde ellos indiquen el nombre con el fin de identificar las diferencias y similitudes que se presentan los seres vivos trabajados.

\section{Actividad 3.}

En grupos de 3 los estudiantes analizan, reconocen y clasifican características de la estructura interna de los seres vivos es decir Taller 1 "¿CÓMO ES LA ESTRUCTURA INTERNA DE LOS SERES VIVOS?". (Anexo 1). Luego los grupos se reúnen para socializar las respuestas, con el fin de que se autoevalúen reconociendo así sus errores y formulen correcciones a estos.

\section{Actividad 4.}

Los estudiantes se organizan en filas, y cada uno lee concentradamente la Lectura 1 “¿QUÉ ES UN MAPA CONCEPTUAL?". Esta lectura se hace con la finalidad de que el estudiante identifique ¿Qué es?, ¿En qué consiste?, ¿Para qué?, ¿Cómo se hace? y ¿Cuál es la importancia de realizar mapas conceptuales? Esta actividad para que los estudiantes construyan un mapa conceptual de lo aprendido hasta el momento. Entendiendo que los mapas conceptuales según Novak y Cañas (2007) son herramientas gráficas para organizar y representar conocimiento que permite la organización jerárquica de éste y su construcción.

\section{Actividad 5.}

Los estudiantes mediante la guía del profesor hacen una lista en el tablero de todos los conceptos y términos discutidos durante las clases anteriores. A partir de estos términos los estudiantes crean un mapa conceptual donde concluyen lo aprendido en la clase. El profesor y los estudiantes elaboran un texto a partir del mapa conceptual "LOS SERES VIVOS" (Anexo 2). Realizado en la Actividad anterior por parte de los estudiantes y bajo la directriz del profesor.

\section{Actividad 6.}

Los estudiantes desarrollan el Taller 2 sobre estructura interna de las plantas y animales: Tejidos, órganos y sistemas. Luego Forman una mesa redonda y bajo la guía del Docente Socializan y debaten las respuestas. 
Edición Extraordinaria. p.p.1057-1066

Memorias del VIII Encuentro Nacional de Experiencias en Enseñanza de la Biología y la

Educación Ambiental. III Congreso Nacional de Investigación en Enseñanza de la

Biología.

\section{Actividad 7.}

Los estudiantes se organizan en filas y cada uno realiza la "Evaluación 1"de lo aprendido hasta ahora, (ver Anexo 3). Luego Los estudiantes se organizan en filas y en sus cuadernos realizan su auto evaluación del examen realizado. Indicando el porqué de sus fallas y a su vez realizando las correcciones respectivas.

\section{CIERRE}

Entre el profesor y los estudiantes a través de participación y debate, construyen conclusiones finales de lo aprendido en lo referente a cómo es la estructura interna de los seres vivos.

\section{Tabla 3. Secuencia didáctica.}

Para el cuarto momento, el cual concierne con la aplicación de la secuencia didáctica, algunas evidencias (Ver imágenes 1,23 y 4) de las actividades $(1,2,7)$ propuestas.

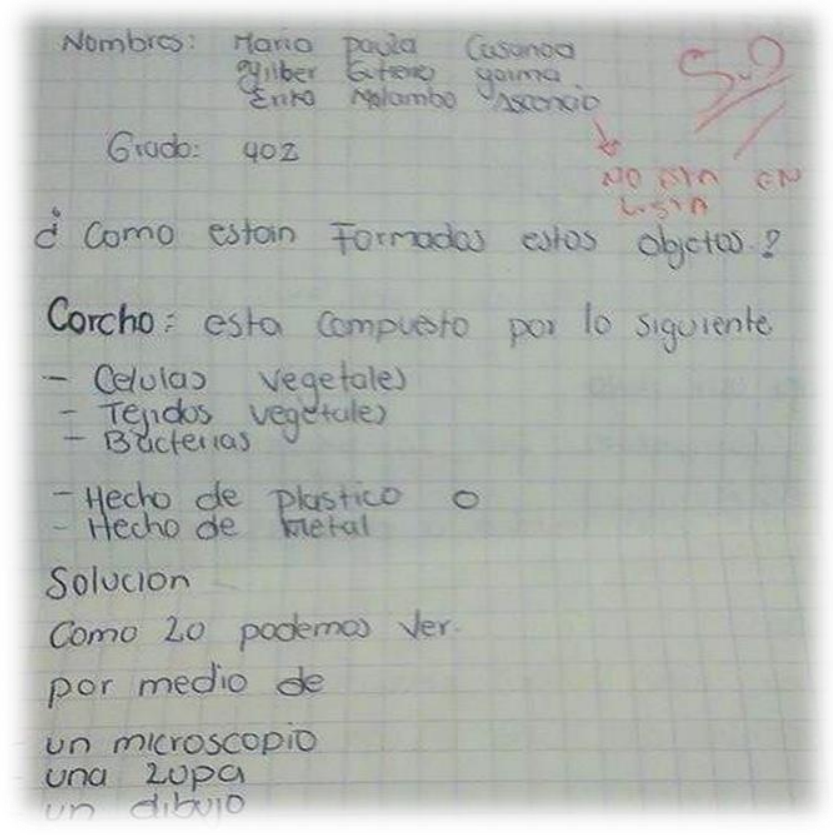

Imagen 1.Actividad 1, Solución a hipótesis propuesta por el estudiante E25.

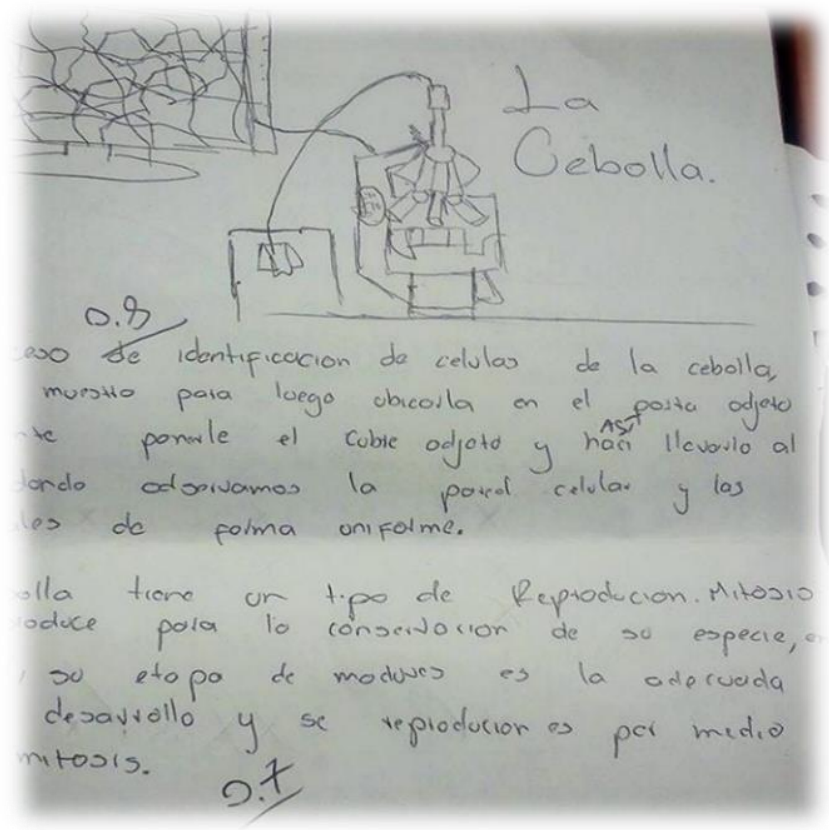

Imagen 2. Evaluación 1 desarrollada por el estudiante E55. 
Memorias del VIII Encuentro Nacional de Experiencias en Enseñanza de la Biología y la Educación Ambiental. III Congreso Nacional de Investigación en Enseñanza de la Biología.

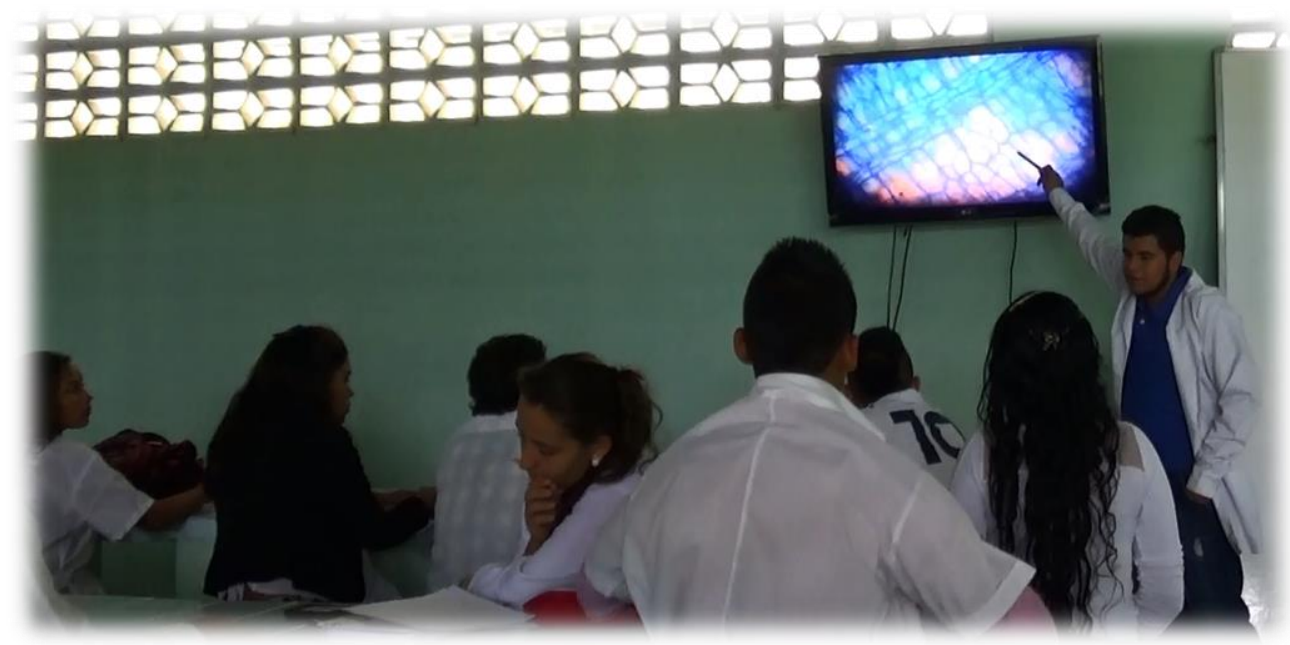

Imagen 3.Aplicacion de la Actividad 2 (Reconocimiento y diferenciación de células de algunos seres vivos)

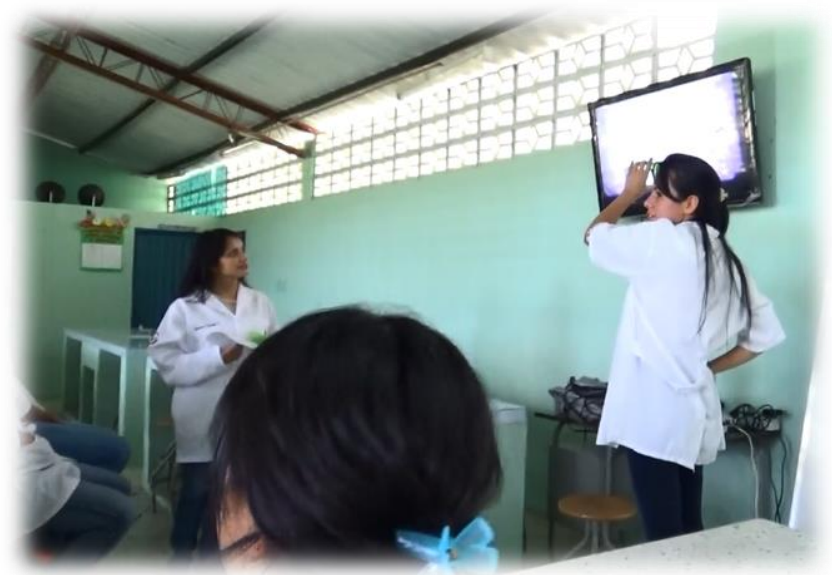

Imagen 4. Socialización y debate de resultados obtenidos por parte de los estudiantes en la Actividad 2.

Para el quinto Momento el estudiante profesor a partir de lo vivido en clase, realiza el diario de campo. A continuación algunos apartes de éste.

\section{Primera Sección sábado 14 de febrero de 2015:}

\section{8:40 am - 10:40 am}

\section{Actividad Clase: ¿Cómo están formadas las cosas?}

"Antes de iniciar la clase tenía algo nervios, pues era la segunda vez como tal daba clase en un colegio oficial, ya que la primera vez fue aplicando una clase de cambios físicos de la materia en estudiantes de grado sexto del colegio María Cristina Arango de la Ciudad Neiva en el seminario de Didáctica II. La enseñanza de mi clase era en el Colegio Juan XXIII del cual soy egresado como 
Memorias del VIII Encuentro Nacional de Experiencias en Enseñanza de la Biología y la Educación Ambiental. III Congreso Nacional de Investigación en Enseñanza de la Biología.

bachiller, el cual se encuentran en un contexto complicado por problemas de orden público. Esta clase tenía algo especial ya que no iba a tratar con niños como estoy acostumbrado en un grado sexto si no con estudiantes de una amplia variedad edades: adolescentes, jóvenes y adultos que están en un rango entre los 15 hasta los 75 años que toman la educación no formal como una alternativa que se acopla a sus situaciones de vida. Al iniciar la primera sesión de la clase tenía que dejar bien en claro cuál era mi posición como maestro, pues a partir de ello tendría la atención y el respeto de mis estudiantes. Por esta razón fui muy amable, cortés, bromista ganando un poco de confianza y seguridad...Luego de esto a la hora de socializar la actividad, se me surgió la idea de escoger algunos de los representantes de los grupos para que realizaran su esquema mental en el tablero y lo explicaran y la cual fue muy a provechosa, a pesar de que no la tenía incluida en mi secuencia o ciclo de clase..."

\section{Conclusión.}

La experiencia de la secuenciación de una clase, su preparación, aplicación y reflexión teniendo en cuanta variables como las dificultades en la enseñanza y aprendizaje de las ciencias naturales, las ideas previas, el interés de los estudiantes y el contexto, nos brinda elementos teóricos y prácticos nos permiten relacionar el saber disciplinar y pedagógico -didáctico en la enseñanza de las Ciencias Naturales dando a ella un sentido distinto.

Para el estudiante profesor en la enseñanza de la estructura de los seres vivos es fundamental movilizar al aula representaciones como situaciones problemas que parten del mundo de la vida del estudiante y prácticas de laboratorio centradas en la cotidianidad y los modelos conceptuales de las ciencias. En este sentido, el estudiante profesor considera que el conocimiento del tema de la materia es necesario, pero no suficiente, para lograr una práctica profesional que vaya direccionándose a ser un maestro ejemplar.

\section{REFERENTES BIBLIOGRAFICOS}

Ibarra. O. (2011). Saber pedagógico y saber disciplinar ¿convergencia o divergencia? PAIDEIA Surcolombiana. Vol.: 15, pp: 90-98.

Menegaz, A. Y Mengascini, A. (2005). El concepto de niveles de organización de los seres vivos en contextos de enseñanza. Enseñanza de las Ciencias, Número Extra, VII Congreso Internacional sobre Investigación en Didáctica de las Ciencias.

Mengascini, A. (2006). Propuesta didáctica y dificultades para el aprendizaje de la organización celular. Eureka sobre Enseñanza y Divulgación de las Ciencias, vol. 3, núm. 3, pp. 485-495 Asociación de Profesores Amigos de la Ciencia: EUREKA Cádiz, España.

Neus Sanmarti (2002).Necesidades de formación del profesorado en función de las finalidades de la enseñanza de las ciencias. Pensamiento Educativo. Vol. 30, pp. 35-60.

Novak, J. D. \& A. J. Cañas (2007). La Teoría Subyacente a los Mapas Conceptuales y a Cómo Construirlos, Reporte Técnico IHMC CmapTools 2006-01, Florida Institute for Human and Machine Cognition, disponible h: http://cmap.ihmc.us/ Publications/ResearchPapers/TheoryUnderlyingConceptMaps.pdf

Porlàn, R. (1993). El diario del profesor. Un recurso para la investigación en el aula. Serie Practica: Sevilla 
Edición Extraordinaria. p.p.1057-1066

Memorias del VIII Encuentro Nacional de Experiencias en Enseñanza de la Biología y la Educación Ambiental. III Congreso Nacional de Investigación en Enseñanza de la

Biología.

Rivera Cañón, L. H. (2013). Enseñanza aprendizaje del concepto de ser vivo en estudiantes de básica primaria. Trabajo de grado para optar al Título de: Magister en Enseñanza de las Ciencias Exactas y Naturales. Universidad Nacional de Colombia. Facultad de Ciencias Exactas y Naturales Departamento de Matemáticas y Estadística. Manizales, Colombia.

Universidad Surcolombiana: Facultad De Educación (2011). Reglamento de Práctica Profesional del Programa Licenciatura en Ciencias Naturales y Educación Ambiental.

\section{ANEXOS}

\section{Anexo 1}

Taller 1

¿Cómo es la estructura interna de los seres vivos?

Nombre de los integrantes:

Grado:

1. En la siguiente tabla se presenta una serie de materiales, indica con una $X$ : si son organismos unicelulares o pluricelulares, si presentan Células Eucariotas o Procariotas y cuáles de ellos presentan ADN, Membrana Nuclear y Reproducción

\begin{tabular}{|c|c|c|c|c|c|c|c|}
\hline CRITERIO & \multirow{2}{*}{ UNICELULAR } & \multirow{2}{*}{ PLURICELULAR } & \multirow{2}{*}{ EUCARIOTA } & \multirow{2}{*}{ PROCARIOTA } & \multirow{2}{*}{ ADN } & \multirow{2}{*}{$\begin{array}{l}\text { MEMBRANA } \\
\text { NUCLEAR }\end{array}$} & \multirow{2}{*}{ REPRODUCCION } \\
\hline MATERIAL & & & & & & & \\
\hline \multicolumn{8}{|l|}{ NARANJA } \\
\hline \multicolumn{8}{|l|}{ CORCHO } \\
\hline \multicolumn{8}{|l|}{ BACTERIA } \\
\hline \multicolumn{8}{|l|}{ МOHO } \\
\hline \multicolumn{8}{|l|}{ CEBOLLA } \\
\hline AGUA & & UNICELULARES & & PLURICELULARES & & & \\
\hline $\begin{array}{l}\text { Respecto a } \\
\text { explica } \angle \mathrm{Por}\end{array}$ & & $\begin{array}{c}\downarrow \\
\text { Formados por } \\
\downarrow\end{array}$ & & $\begin{array}{c}\downarrow \\
\text { Formados por } \\
\downarrow\end{array}$ & & & $\begin{array}{l}\text { tan reproducción } \\
\text { lé, donde, cuando }\end{array}$ \\
\hline y como se re & & UNA CELULA & & DOS O MAS CELULAS & & & \\
\hline
\end{tabular}

Anexo 2

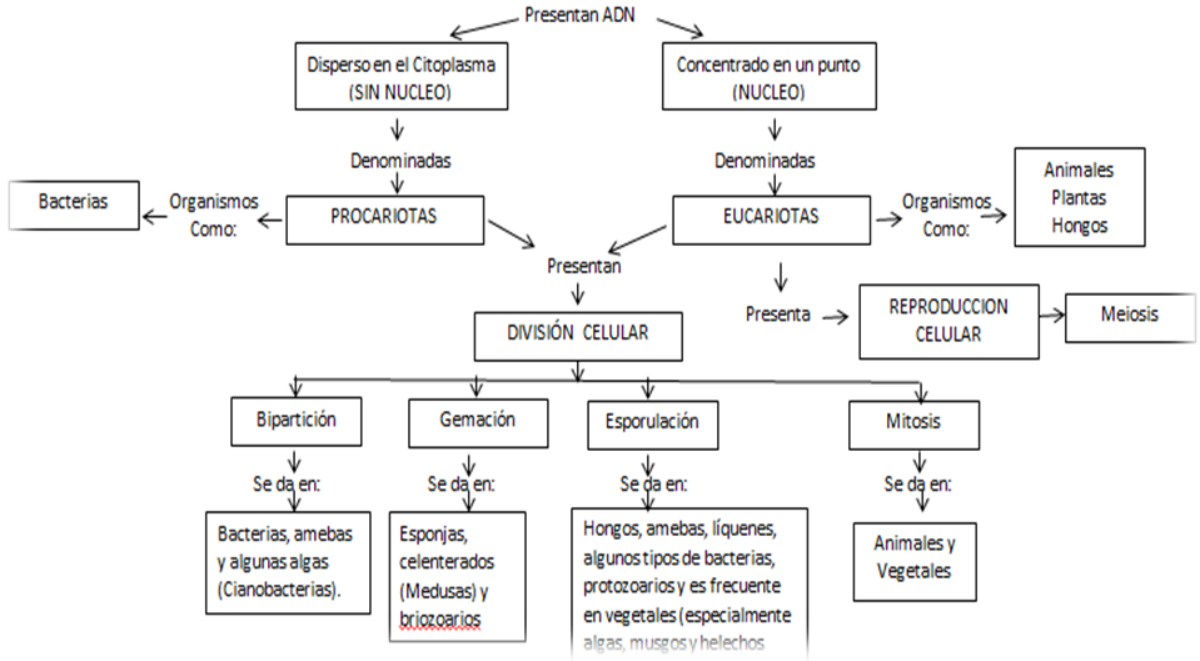


Edición Extraordinaria. p.p.1057-1066

Memorias del VIII Encuentro Nacional de Experiencias en Enseñanza de la Biología y la Educación Ambiental. III Congreso Nacional de Investigación en Enseñanza de la Biología.

\section{Anexo 3.}

\section{INSTITUCIÓN EDUCATIVA JUAN XXIII \\ Primer Examen \\ Estructura interna de los seres vivos \\ Grados 401, 402 y 403}

Nombre:

Fecha:

Grado:

1. acuerdo a la observación de muestras de los siguientes materiales en el microscopio en la práctica de laboratorio, en cuanto a las células observadas en cada uno de estos materiales. Indica con una X cuáles de ellas se consideran unicelular, pluricelular, eucariota, procariota. Cuáles de ellas provienen de un animal, vegetal hongo o bacteria.

\begin{tabular}{|c|c|c|c|c|c|c|c|c|}
\hline CRITERIO & \multirow{2}{*}{ UNICELULAR } & \multirow{2}{*}{ PLURICELULAR } & \multirow{2}{*}{ EUCARIOTA } & \multirow{2}{*}{ PROCARIOTA } & \multirow{2}{*}{ ANIMAL } & \multirow{2}{*}{ VEGETAL } & \multirow{2}{*}{ HONGO } & \multirow{2}{*}{ BACTERIA } \\
\hline MATERIAL & & & & & & & & \\
\hline Моно & & & & & & & & \\
\hline CORCHO & & & & & & & & \\
\hline CEBOLLA & & & & & & & & \\
\hline $\begin{array}{l}\text { AGUA } \\
\text { CONTAMINADA }\end{array}$ & & & & & & & & \\
\hline $\begin{array}{l}\text { PALO DE HELADO } \\
\text { USADO }\end{array}$ & & & & & & & & \\
\hline EaPERMATOZOIDE & & & & & & & & \\
\hline
\end{tabular}

2. De acuerdo a lo anterior recrea el proceso de identificación de las células, de uno de los materiales anteriores. Explica de manera escrita y gráfica.

3. Al frente de cada ser vivo escribe si está conformado de células o tejidos o las dos. Explica tu respuesta:

a. Bacteria.

b. Hormiga

c. Árbol.

d. Hongo

e. Piedra

f. Niño

\section{Fuente: Estudiante Profesor.}


Bio -grafía. Escritos sobre la Biología y su Enseñanza. ISSN 2027-1034

Edición Extraordinaria. p.p.1057-1066

Memorias del VIII Encuentro Nacional de Experiencias en Enseñanza de la Biología y la Educación Ambiental. III Congreso Nacional de Investigación en Enseñanza de la Biología. 